\title{
Secrets of fracking fluids pave way for cleaner recipe
}

\section{Disclosure of chemicals used in hydraulic fracturing will empower green chemistry.}

\section{BY JEFF TOLLEFSON}

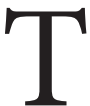
he myriad liquid concoctions used in hydraulic fracturing make for quite a recipe book. Since January 2011, FracFocus, an online chemical-disclosure registry, has assembled a list of the mixtures used at more than 52,000 oil and gas wells across the United States. In these data, geochemist Brian Ellis sees opportunity. He plans to mix different chemicals into oil- and gas-rich shale rock inside a pair of high-pressure chambers that he is building. This will allow him to explore the reactions that occur when these 'fracking' fluids are injected deep underground.

The fluids, which are mixed with sand, are predominantly water, laced with $1 \%$ 'special sauce. The recipes for that fraction - a mixture that includes acids, solvents and corrosion inhibitors - were until the last few years secrets guarded by the companies that seek to penetrate shale formations to release stores of fossil fuels. But in the face of widespread concern about water contamination, 21 US states have adopted mandatory disclosure rules for the mixtures, making it easier for scientists such as Ellis, of the University of Michigan at Ann Arbor, to assess their impacts.

Much of the data end up in registries such as FracFocus, which is overseen by state energy and water organizations (see 'A recipe for fracking'). "There are still a lot of bugs, but the vast majority of companies are now disclosing their chemicals," says Scott Anderson, a senior policy adviser for the Environmental Defense Fund in Austin, Texas, which advocates for greener fracking procedures.

More than 500 companies have reported data to FracFocus so far. Academic researchers, advocacy groups and companies are now poring over those recipes to assess their toxicity in the hope of narrowing them down to a group of environmentally acceptable ones - and perhaps spurring the synthesis of even greener alternatives.

The boom in the disclosure of frackingfluid components has occurred despite the fact that the federal government has yet to weigh in with its own rules. The Department of the Interior has proposed requiring the disclosure of chemicals used during hydraulicfracturing operations on public lands, but much of the current oil and gas development

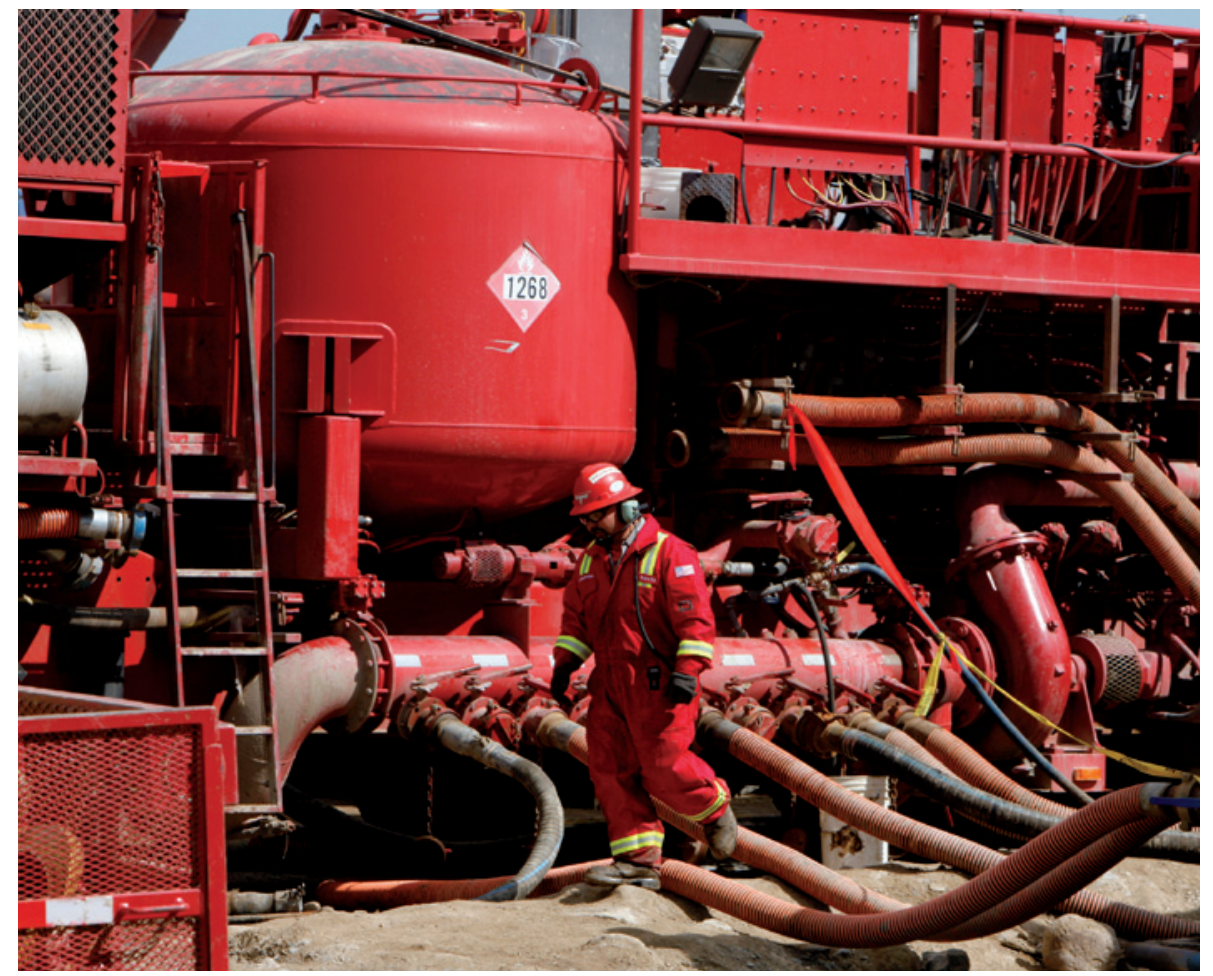

The chemicals used in hydraulic fracturing to extract oil and gas are being disclosed to online registries.

is taking place on private land. Many companies are volunteering the information anyway, even in states that have no disclosure requirements. And companies that do the hydraulic fracturing, such as Halliburton and Baker Hughes, both based in Houston, Texas, are developing their own chemical-assessment programmes in an apparent effort to address public concerns and reduce their environmental footprint.

The data in these registries, although increasingly abundant, remain incomplete, unconsolidated and difficult to compare. The European Union is phasing in a unified chemical-regulation programme that governs reporting across all commercial sectors. Energy companies operating in the North Sea, for example, must all play by the

$\rightarrow$ NATURE.COM

For concerns about the impact of fracking, see: go.nature.com//93vas same rules and abide by strict reporting requirements. But in the United States, the regulations on chemical reporting remain a mixture of state and national policies that vary by industry.

Even in states with disclosure laws, companies can omit information in the interests of protecting intellectual property. For example, a subsidiary of ExxonMobil, based in Irving, Texas, declined to list the components of a gelling agent - used to help to suspend sand in water - at one of its wells in Wyoming, calling the information a "trade secret".

The result is that companies are still operating under their own risk assessments and not disclosing all of the information that might be needed for independent verification. "If everybody has a different definition of what is hazardous and doesn't fully disclose the chemicals they use, then it is going to be awfully difficult to compare," says Lauren Heine, co-director of Clean Production Action, an advocacy group based in Somerville, Massachusetts.

Heine's group is sifting through company disclosures to perform a risk assessment on the most commonly used chemicals. The effort is designed to provide a single point of 
comparison so that scientists, industry and the public can make informed decisions about which chemicals are best.

Daniel Durham, who heads a chemicalassessment programme at the Houston-based energy company Apache, says that although Heine's effort is promising, companies do not need to wait. The US Environmental Protection Agency (EPA) already maintains its own public registry of preferred chemicals for various industrial processes. Companies that want to register their chemicals provide the EPA with toxicity and environmental-assessment data; the registry also allows companies to keep certain data confidential if intellectual property is involved.

The upshot is a growing - albeit incomplete - list of preferred chemicals that companies such as Apache can choose from as they design their fracking fluids. A company that wants to avoid using a solvent such as ethylene glycol monobutyl ether, for example - used to reduce viscosity but possibly toxic to the endocrine system - could look through the EPA list for alternatives. "It's a very good road map to green chemistry," Durham says.

Eventually, Durham hopes that researchers will help to develop novel chemicals that could be used to make the entire hydraulicfracturing process cleaner and more efficient.

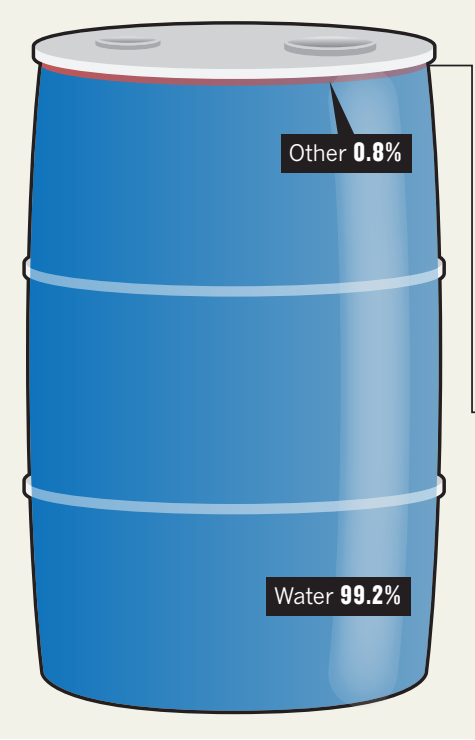

\section{A RECIPE FOR FRACKING}

Once a well has been drilled and sealed off, companies inject hydraulic fracturing fluids at high pressures to break up the rock and allow oil and gas to flow. These fluids, which are mostly water, are mixed with sand; this is used to prop fractures open. Acids dissolve minerals and initiate cracks. Gelling agents are used to suspend sand in the water, and breakers delay breakdown of the gels. Friction reducers lubricate the fissures. Pipes are protected by corrosion and scaling inhibitors, biocides and chemicals that control reactions with iron and clay.

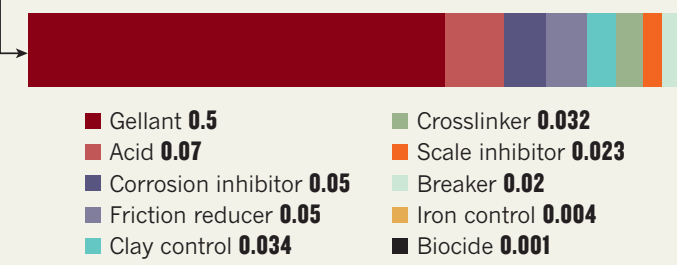

Scientists such as Ellis could play an important part.

Ellis wants to know whether fracking fluids are contributing to geochemical reactions within the shale rock that might free up potentially dangerous metals and radionuclides, such as arsenic, barium, strontium and uranium. These elements are often found in trace concentrations in the waste water produced by oil and gas companies, but can also be found naturally in groundwater. Ellis eventually hopes to help companies to select better chemicals that would minimize the potential for contamination and the need for wastewater treatment. But for now, he says, he is focused on the basic science. "Fundamentally, I just want to understand those reactions a little better." -

\section{More cuts loom for US science}

\section{Stalemate in Congress puts spending plans on hold.}

\section{BY LAUREN MORELLO}

$\mathrm{L}$ aura Niedernhofer is counting her pennies. The mid-career molecular biologist moved last year to the Scripps Research Institute's campus in Jupiter, Florida — a risky decision that saw her building a new laboratory group at a time when the US government was cutting its support for science. In June, Niedernhofer abandoned one of her main lines of research - reducing the toxicity of cancer drugs - after the National Institutes of Health (NIH) rejected her grant application. In July, the agency approved a second grant, allowing her to keep another research thrust alive - on the molecular mechanisms of ageing. But the NIH cut the award by $18 \%$, preventing her from hiring an additional postdoctoral researcher.

Niedernhofer is not alone. In a survey of more than 3,700 US scientists released on 29 August by the American Society for Biochemistry and Molecular Biology in Rockville, Maryland, onethird said that they had laid off researchers, and close to two-thirds had seen their funding fall

since 2010. Federal spending on research and development has declined by $16.3 \%$ since 2010 , the fastest drop in a three-year period since the end of the space race in the 1970s, according to an analysis published on 3 September by the American Association for the Advancement of Science in Washington DC.

The most drastic reduction occurred on 1 March, when across-the-board budget cuts known as sequestration lopped $5 \%$ from the budgets of most government agencies. Science

\section{"There is contimuing pressure for additional budget cuts as a price for raising the debt ceiling."} powerhouses such as the NIH in Bethesda, Maryland, and the National Science Foundation in Arlington, Virginia, began to scrimp by reducing the values and durations of grants, and the number of recipients per application cycle.

The situation could worsen in the coming months. Congress, which returned to Washington DC this week, has made little progress on setting government spending for the 2014 fiscal year, which begins on 1 October. An attempt by a group of Republican senators and the White House to negotiate an agreement on deficit reduction broke down in late August, and since then the crisis in Syria has diverted the attention of Congress. To avoid a government shutdown, lawmakers are expected to extend current funding levels until December. That extension, known as a continuing resolution, would run out at about the same time that the country confronts another financial matter: surpassing its borrowing limit, or debt ceiling.

That could set up a budget battle royal in the next few months. A similar fight in the summer of 2011 led to the law that created sequestration; it specifies annual spending reductions until 2021, if Congress does nothing to override it. The next round of cuts, scheduled to take effect in January 2014, would trim spending to $2 \%$ below the already-whittled-down 2013 level.

Indications of how the various science agencies will fare can be found in Congress's 